\title{
Green Clubs and Voluntary Governance: ISO 14001 and Firms' Regulatory Compliance
}

\author{
Matthew Potoski \\ Aseem Prakash University of Washington
}

\begin{abstract}
Voluntary programs have become widespread tools for governments and nongovernmental actors looking to improve industry's environmental and regulatory performance. Voluntary programs can be conceptualized as club goods that provide nonrival but potentially excludable benefits to members. For firms, the value of joining a green club over taking the same actions unilaterally is to appropriate the club's positive brand reputation. Our analysis of about 3,700 U.S. facilities indicates that joining ISO 14001, an important nongovernmental voluntary program, improves facilities' compliance with government regulations. We conjecture that ISO 14001 is effective because its broad positive standing with external audiences provides a reputational benefit that helps induce facilities to take costly progressive environmental action they would not take unilaterally.
\end{abstract}

$\mathrm{V}$ oluntary programs are a fast growing and increasingly important policy tool (Haufler 2001). The sponsors of voluntary programs include governments, business groups, and nongovernmental organizations (NGOs). We conceptualize voluntary programs as clubs (Prakash 2000a), drawing on the theoretical insights proposed by Buchanan (1965). Clubs promulgate standards of conduct targeted to produce public benefits by changing members' behaviors. In return, club members receive excludable and nonrivalrous (club) benefits, such as affiliation with the club's positive "brand name." Successful clubs induce members to voluntarily undertake progressive environmental action beyond what they would have taken unilaterally. This is because the costs of joining the club and adhering to its standards are offset by the tangible and/or intangible benefits accruing to firms via the clubs' positive brand reputation.

In this article, we investigate ISO 14001, a voluntary program sponsored by the International Organization for Standardization, in light of club theory. ISO 14001 is perhaps the most important and visible voluntary environmental program with over 36,000 registered facilities worldwide as of 2001, including 1,645 in the United States, and a 50\% per year growth rate since 1996 (ISO 2001). Our central question is whether joining ISO 14001 reduces the amount of time member facilities spend out of compliance with government regulations. Drawing on the ISO 14001 literature, supplemented with interviews with plant managers of ISO 14001 certified facilities and U.S. environmental regulators, we show that ISO 14001 requires members to adopt extensive (and costly) environmental management systems (EMS) and that ISO 14001 enjoys a strong positive brand reputation. We then present a quasi-experimental empirical analysis of nearly 3,700 facilities regulated under the U.S. Clean Air Act. The results imply that as a group ISO 14001 certified facilities have better compliance records than if they had not joined the program. Importantly, this result persists even while controlling for facilities' compliance histories as well as addressing potential endogeneity issues between facilities'

Matthew Potoski is Assistant Professor of Political Science, 519 Ross Hall, Iowa State University, Ames, IA 50010 (potoski@iastate.edu). Aseem Prakash is Associate Professor of Political Science, 39 Gowen, Box 353530, University of Washington, Seattle, WA 98195 (aseem@u.washington.edu).

This is a revised version of a paper presented at the 2003 Annual Meeting of the Midwest Political Science Association, and the 2003 Association of Policy Analysis and Management Conference. We thank Trevor Brown, Dan Fiorino, Devin Joshi, Kathryn Harrison, Robert Lowry, Mark Lubell, Erik Lundsgaarde, Peter May, Frank Montabon, Tom Rice, Mark Smith, Michael Ward, Soren Winter, the AJPS editors, and the AJPS reviewers for comments on previous drafts. Matthew Potoski acknowledges financial support from the Iowa State University Institute of Science and Society and the Iowa State University College of Liberal Arts and Sciences. Aseem Prakash acknowledges support from University of Washington's Royalty Research Fund. Sarah Edrington, Joseph Haley, Melissa Homrig, and Jason Stonerook provided excellent research assistance.

American Journal of Political Science, Vol. 49, No. 2, April 2005, Pp. 235-248 
regulatory performance and their decision to join ISO 14001.

Firms' noncompliance with government regulations may stem from willful avoidance or ignorance of what government regulations require. We conjecture that ISO 14001's mandated third-party auditing mitigates willful noncompliance by compelling members to measure up to club standards while ISO 14001's EMS standards address noncompliance stemming from ignorance by directing members' attention to root causes of regulatory noncompliance (Brehm and Hamilton 1996; Winter and May 2001). In the remainder of this article, we first introduce voluntary environmental programs and place them in the context of governmental regulation and club theory. We then summarize ISO 14001 and its key institutional features. Next, we present our data and analytic methods for our empirical evaluation of ISO 14001. Finally, we discuss the results of our analysis and conclude by discussing the implications of our study.

\section{Mandatory Regulations, Voluntary Programs, and Club Goods}

In its most common form, regulation involves the use of governmental authority to permit, prescribe, or prohibit private actors' behavior. The command and control approach represents the traditional style of government regulation; regulators prescribe legally binding performance standards such as emissions limits and/or the use of specific (such as "best available") production technologies. Government regulators monitor firms' compliance with these standards and sanction those found out of compliance. In the United States, federal command and control regulation expanded in the early 1970s with the passage of major environmental legislation such as the Clean Air Act and the Clean Water Act. By the 1980s, it became clear that while initially successful (Greenstone and Chay 2004), diminishing returns to command and control regulation were setting in (Ayres and Braithwaite 1992; Fiorino 1999). Businesses complained that technologyforcing regulation coupled with rigid enforcement created high compliance costs that hurt productivity and profits (Jaffe et al. 1995; Walley and Whitehead 1994). For regulators, command and control has been resource and enforcement intensive. Declining agency budgets (especially in the United States) relative to regulatory mandates may undermine enforcement frequency and efficacy (Carpenter 1996; GAO 1983; Wood and Waterman 1993). To illustrate, between 1996 and 1998, less than 1\% of the 122,226 large regulated facilities in the United States were inspected for all three pollution media (Hale 1998). While command and control regulation may be more effective than no regulation, its high costs suggest there may be other tools such as voluntary programs that can supplement command and control.

Voluntary programs require participants to incur specific private costs to produce public goods. In return, participants receive benefits that are excluded from nonparticipants, thereby creating incentives to join the program. ${ }^{1}$ For firms, the benefits of membership over taking the same actions unilaterally are the excludable branding certification that allows members to publicize their club membership and thus claim credit for their proenvironmental activities. ${ }^{2}$ Thus, for participating firms, the benefits of such voluntary programs are impure public goods, or more specifically club goods (Buchanan 1965; Cornes and Sandler 1996). ${ }^{3}$

Club sponsors develop, monitor, and enforce their club's membership standards. Membership standards generally impose nontrivial costs on members, such as adopting stringent EMS. For members, the main costs of joining the club are therefore generally not direct

${ }^{1}$ Government-sponsored voluntary programs can offer more tangible excludable benefits such as regulatory relief, along with less tangible rewards such as goodwill that comes from association with the program's positive reputation. Since nongovernmental voluntary programs, including ISO 14001, generally offer only less tangible benefits, this article focuses on the reputational benefits of club membership.

${ }^{2}$ The average per member cost of producing the club reputation declines with additional members. At some point crowding sets in; if membership is universal, the club does little to distinguish environmentally progressive members.

${ }^{3}$ We recognize that sometimes firms undertake progressive environmental action for private benefits: reducing pollution may lower production costs. Such progressive firms may be able to join ISO 14001 at smaller marginal costs. However, our analytical puzzle addresses a different issue: what induces firms to join voluntary programs as opposed to adopting similar policies unilaterally. We argue that the club's reputation is the key benefit that induces program participation. Analytically, firms' action induced by private benefits alone is the baseline against which we look to gauge the efficacy of environmental programs. The value added of a voluntary environmental program is the extent to which the excludable benefit induces progressive action beyond what private motives alone would produce. This is not to say that joining voluntary programs does not create private benefits. There are often private benefits to taking the action required to join a voluntary program, but such benefits are not the discriminating factor that induces firms to join a club because a firm can produce private benefits through unilateral action as well. Anticipating our empirical test, we look to demonstrate that ISO 14001 has a strong club benefit (via its positive brand reputation), and that on average ISO 14001 certified facilities have better regulatory performance than they would have achieved had they not joined the program. 
payments to club sponsors. ${ }^{4}$ Rather, they are the monetary and nonmonetary costs of adopting and adhering to the club's program requirements. Adherence to these requirements produces the club's targeted public good such as a cleaner environment or better regulatory compliance. The production of such public goods creates goodwill for the club among external audiences, thereby enhancing the reputation of the program and its members.

The club's positive brand identity potentially benefits club members in several ways. In its broadest sense, it reduces transaction costs for various external audiences to distinguish members from nonmembers. Credible clubs provide valuable information about members' progressive environmental activities because so much of firms' environmental activities are unobservable to most external audiences (though different audiences may have different information about firms' performance). Affiliation with the club reputation is thus akin to building organizational reputations: their value is in how they shape external actors' interactions with the organization (Carpenter 2001). We use the term "external audiences" to refer to individuals and groups that might reward the firm for taking pro-environmental action. Audiences may thus include consumers, stockholders, residents of neighborhood surrounding the firm, and environmental groups. Rewards may be monetary, such as buying products because they were produced in an environmentally progressive way, or nonmonetary, or not directly monetary, such as avoiding negative publicity from an environmental group protesting a firm's environmental practices (Gunningham, Kagan, and Thornton 2003; Hoffman 1997; Prakash 2000b). The key conceptual distinction for our purposes is that clubs' excludable benefits are not the rewards members receive from external audiences for taking specific environmental action. Rather, excludable benefits stem from membership in ISO 14001, which provides a credible signal of a firm's overall approach to environmental governance.

\section{ISO 14001}

The International Organization for Standardization, the Geneva-based international body of national standards institutions, launched ISO 14001 in 1996. Founded in

\footnotetext{
${ }^{4}$ Analytically, we can identify two categories of costs to club membership: an initiation fee and ongoing membership dues. Such costs are tangible as well as intangible. For green clubs, initiation fees are reflected in the costs of receiving initial certification as bona fide members. Membership dues are the ongoing costs of adhering to those membership standards over time.
}

1947, ISO has established over 12,000 international technical standards to facilitate international trade and commerce. Building on ISO 9000, the successful voluntary code for quality management launched in the 1980s, in October 1996 ISO launched the ISO 14000 series, consisting of a guideline standard (ISO 14001) that members must adopt, and several nonmandatory guidelines governing environmental labeling (14020 and 14021), environmental performance evaluations (14031), and lifecycle assessment (14040-43, 14048-49). To receive ISO 14001 certification, a facility must undertake an initial comprehensive review of its environmental practices and systems, formulate and implement an action plan for environmental management, identify internal governance responsibilities for environmental issues, and have a plan to correct environmental problems. Although firms can self-audit and declare themselves to be in compliance, ISO strongly encourages firms to receive third-party audits and certification (ISO 2002).

A key policy question is whether joining the program improves members' performance beyond what members would otherwise achieve. We look to show that not only do ISO 14001 members have superior compliance with governmental regulations (a public good), but also that the cost of satisfying club requirements is nontrivial and that ISO 14001 provides excludable benefits that induce members to incur these costs. Consequently, club members adopt an EMS, subject themselves to third-party audits, and take actions beyond their premembership levels.

\section{ISO 14001 Costs}

The explicit goal of ISO 14001 is to improve businesses' regulatory and environmental performance by having participating firms adopt stringent EMSs (ISO 2002). The theory is that establishing high-quality EMS improves firms' performance. The monetary and nonmonetary costs of establishing an ISO 14001 EMS, having it certified and then maintaining it, are nontrivial. In monetary terms, the initial cost of establishing an EMS and having it audited by a third party can range from $\$ 25,000$ to over $\$ 100,000$ per facility (Kolk 2000). For a moderatesized firm with 10 facilities, initial monetary costs could range from $\$ 250,000$ to $\$ 1,000,000$. The ongoing costs of maintaining ISO 14001 certification are also important, including the time, money, and expertise for dayto-day operations and preparing for future annual recertification audits. Managers at three ISO 14001 certified facilities (see below) we interviewed all noted that the "bureaucratic" or "paper work" costs of ISO 14001 were substantial. William Glasser of the U.S. EPA notes that 
"large facilities spend on average about $\$ 1 \mathrm{M}$ in sunk transaction costs to pursue certification." ${ }^{5}$ In his analysis of firms' "beyond compliance" environmental decisions, Prakash (2000b) reports that both Baxter and Eli Lily hired additional staff to cope with the paper work and managerial requirements of their ISO 14001 certified EMS. Finally, in nonmonetary terms, ISO 14001 external audits may uncover firms' regulatory violations (Kollman and Prakash 200; Potoski and Prakash 2004a). Firms may be more reluctant to conduct audits without attorney-client privilege protections because regulators may punish selfdisclosed violations (Pfaff and Sanchirico 2000).

\section{Excludable Benefits: The ISO 14001 Brand}

ISO 14001's primary excludable benefit is its brand identity. Member firms benefit from a positive, widely recognized club brand in several ways. Our goal here is not to specify every mechanism by which club reputations creates benefits for members, but rather to show that an important incentive for joining ISO 14001 is its positive brand reputation.

The sponsoring organization, the International Standards Organization is a management standards leader. ISO 14001 is the largest and most widely recognized voluntary environmental program in the world. The growth of ISO 14001 is quite impressive given its recent vintage: there are nearly 50,000 certified facilities in about 118 countries (ISO 2003). Indeed, members can use ISO 14001 as an important external relations tool. A quick scan of Web sites shows that virtually all the major auto manufacturers in the United States are moving toward certifying all their facilities. Honda's Web site boasts "All major Honda plants worldwide already meet the toughest international environmental management standards (ISO 14001)"; Ford Motor Company has also been requiring that its suppliers receive certification. An economic development official in southeastern Iowa reported that several local farms recently formed an ISO 14001 certified cooperative. Their hope was that certification would signal sound management practices to attract biotech research investment.

To further evaluate ISO 14001's positive brand reputation, we draw on semistructured interviews with government officials and facility environmental managers, coupled with evidence drawn from the literature on the program. ${ }^{6}$ For our plant manager interviews, we began

${ }^{5}$ Email response, 01/29/2004.

${ }^{6}$ Plant manager interviews were conducted during the spring of 2003 and government regulator interviews during the fall of 2003 and winter of 2004. with general questions about the costs and benefits of ISO 14001, with more specific follow-up probes. Plant managers offered evidence of what we would call a positive brand identity for ISO 14001, though only one noted that certification was a signal to consumers. This manager noted, "If I'm buying a vehicle and I'm somewhat environmentally conscious and Company A is [ISO 14001] certified and Company B is not, being certified gives a message that Company A is more environmentally sensitive." Another manager stated that ISO 14001 certification raised awareness among suppliers and vendors that the firm was attentive to environmental issues, though she was skeptical that most ISO 14001 was recognized by consumers. The third manager was disappointed that her parent corporation did not use ISO 14001 certification more aggressively in marketing. ISO 14001's positive brand name is evident in how these facilities advertised certification locally: one manager reported that the local newspaper published a favorable article when the facility received ISO 14001 certification, although the facility's earlier pollution prevention award received more prominent press coverage. A manager at another certified facility reported flying an ISO 14001 flag on the facility flagpole.

ISO 14001 has a positive brand image among government regulators. All in all, we spoke with nine state and federal environmental regulators, all of whom recognized ISO 14001 as an important voluntary program that indicated members were making some degree of commitment to environmental action. Jeff Smoller of Wisconsin DNR noted that although very few regulators would "give ISO 14001 certified facilities an auto pass,” ISO 14001 was the "gold standard" among EMS based voluntary regulations. Indeed, other EMS standards are judged on their functional equivalence to ISO 14001. Doug Smith of the EPA, Region 10, noted that "it requires a lot of work and resources to establish solid EMS and get it audited. ISO 14001 signals firms' commitment to environmental excellence." Susan Roothaan of Texas DNR also noted that ISO 14001 signals firms' intent to better comply with the law. ${ }^{7}$

\section{ISO 14001 and Club Performance}

The fundamental test for any voluntary program is whether joining the program improves performance beyond what participants would otherwise achieve. Applying club theory to ISO 14001 suggest grounds for why the program can be effective. It has nontrivial costs,

${ }^{7}$ Interview with Jeff Smoller, 09/15/2003; Interview with Doug Smith, 01/24/2004; Email response from Susan Roothaan, $12 / 16 / 2003$. 
suggesting that joining ISO 14001 requires members to establish EMS that some members might not otherwise take on. ISO 14001 also has important excludable club benefits. ISO 14001's brand identity is broadly recognized and positive; facilities' affiliation with the program can enhance their standing with regulators and other external audiences. The final link in our theoretical chain is between facilities joining ISO 14001 and the club producing a broader public good, compliance with governmental regulations in our case. If facilities' noncompliance stems from poor management, such as ignorance of regulatory requirements (Brehm and Hamilton 1996; Winter and May 2001) or other internal problems (Dasgupta, Hettige, and Wheeler 2000), ISO 14001's EMS focus may help improve members' regulatory performance. Effective EMS can help facilities identify and correct regulatory problems before they become violations. Our central hypothesis therefore is simply:

Hypothesis 1: Joining ISO 14001 improves facilities' compliance with environmental regulations.

Empirically demonstrating performance improvement is challenging, although our evidence below, based on a quasi-experimental comparison of ISO 14001 certified and noncertified facilities, suggest that ISO 14001 certification improves facilities' compliance with environmental regulations. While we do not have direct evidence for why ISO 14001 accomplishes this, it is a compelling question given that other voluntary programs have apparently struggled to improve members' performance (King and Lenox 2000; Welch, Mazur, and Bretschneider 2000). We speculate on reasons for ISO 14001's efficacy in the conclusion.

Our study of ISO 14001 is significant in light of critics' charges that voluntary programs are "greenwashes" that do little to improve members' performance. While club theory suggests reasons for why ISO 14001 can be effective, there are grounds for skepticism. First, ISO 14001 is sponsored by a nonprofit, nongovernmental organization and was developed with heavy input from multinational corporations. Environmental groups are suspicious of self-regulation, particularly in light of recent scandals in the accounting industry. Second, ISO 14001 has loose boundary conditions: all firms are eligible for ISO 14001 membership, even those with poor compliance records, so long as they are willing to take on the costs of establishing and maintaining a certifiable EMS. Contrast this with some state and federal government voluntary programs (the so-called performance track programs) that are limited only to firms with established records of superior performance. Third, because membership does not require investment in assets specific to ISO 14001, firms may have incentives to behave opportunistically by joining ISO 14001 without following its mandate (Williamson 1985). Fourth, ISO 14001 does seem to not have mechanisms for sanctioning members who fail comply with club standards, although it does require annual recertification audits. Fifth, ISO 14001 does not require members to demonstrate improvements in regulatory compliance to maintain membership. It only seeks their commitment to do so and views the establishment and maintenance of an EMS as evidence of such commitment.

Recent literature has examined the efficacy of green clubs in terms of firms' environmental and regulatory performance. The evidence on environmental performance is mixed. Khanna and Damon (1999) find that the releases of the chemicals targeted by the U.S. EPA's 33/50 program declined significantly post-adoption; hence this voluntary program was efficacious. The American Chemistry Council (formerly, the Chemical Manufacturing Association) requires its members to join its "Responsible Care" program and threatens to revoke the membership of companies that consistently fall short of Responsible Care's practices (King and Lenox 2000). Like ISO 14001, Responsible Care is an EMS program, but unlike ISO 14001 it did not appear to improve members' performance, at least in terms of their pollution emissions (King and Lenox 2000). Members of the U.S. EPA's Climate Change program "voluntarily promise" to reduce pollution emissions, but Welch, Mazur, and Bretschneider (2000) found that participating electric utilities did not reduce their $\mathrm{CO}_{2}$ emissions more than nonparticipants. Regarding regulatory performance, Dasgupta, Hettige, and Wheeler (2000) report that adopting environmental management practices along the lines prescribed by ISO 14001 improved Mexican facilities' self-reported compliance with public law.

\section{ISO 14001 and Regulatory Compliance: Empirical Model}

To evaluate our central hypothesis that joining ISO 14001 improves facilities compliance with environmental regulations, we present a large empirical analysis comparing the regulatory records of certified and noncertified facilities, controlling for nonrandom assignment between certification and noncertification along with other intervening factors. Our focus is on facilities regulated under U.S. state and federal air pollution regulations. Facilities in our sample meet air pollution emissions thresholds in order to be tracked by the EPA's Toxics Release Inventory 
(TRI) program and are classified as "major sources" under U.S. clean air laws. We examine air pollution regulation because it is an important policy area and because states exercise some degree of influence in shaping their own approach to clean air regulations (Gerber and Teske 2000; Potoski 2001; Ringquist 1993), allowing us to explore how state policy variation affects facilities' responses ISO 14001. Information on facilities' regulatory compliance comes from the AIRS/AFS subsystem of the EPA's Integrated Data for Enforcement Analysis (IDEA) system. Emissions data are from the EPA's Toxics Release Inventory. Other measures are drawn from Dunn and Bradstreet's Million Dollar Directory and other sources as discussed below. Our sample contains 3,709 facilities, 151 (4\%) of which were ISO 14001 certified as of December 2001.

Our analyses are complicated first by the fact that facilities' decisions about whether to participate in ISO 14001 are likely to be endogenous to their regulatory performance. That is, some of the observed and unobserved factors that influence joining ISO 14001 are also likely to influence regulatory performance (Khanna and Damon 1999; Welch, Mazur, and Bretschneider 2000). We use a treatment effects model to account for the effect of nonrandom assignment among ISO 14001 certified and noncertified facilities (Greene 1999; for applications see Lubell et al. 2002 and Schneider et al. 2003). Similar to a Heckman correction, this is a two-step model that first estimates a probit model for why facilities join ISO 14001 and then a linear model of facilities' regulatory performance with independent variables including a measure of whether a facility joined ISO 14001, adjusted for potential endogeneity between facilities' decisions to join ISO 14001 and their regulatory compliance. ${ }^{8}$ In controlling for the selection of facilities' into ISO 14001, we seek to isolate the impact of facilities' ISO 14001 membership on regulatory compliance from other factors that induce facilities to join ISO 14001 and comply with regulations in the first place.

Our measure of regulatory compliance identifies whether or not a facility is out of compliance for at least one air pollutant or for the procedural requirements of its

\footnotetext{
${ }^{8}$ Given that the occurrence of an ISO 14001 certification "event" is quite rare, we might ideally use a selection function such as a "log-log model" that accounts for the asymmetry between the likelihood that an event occurs and that it does not occur (see Long 1997, 51-52). Unfortunately, to our knowledge no one has yet incorporated such a model in a treatment effects analysis and its properties remain unexplored. We experimented with a two-stage procedure, estimating first a log-log model for joining ISO 14001 and then submitting the predicted values into an OLS analysis of compliance. The results were essentially the same as those presented here.
}

operating permit, as reported in the AIRS/AFS data system. Compliance is the proportion of months in 2000 and 2001 that a facility was listed as out of compliance. ${ }^{9}$ Another strategy would be to examine the effect of ISO 14001 certification on pollution emissions; we intend to conduct this analysis once 2000-2001 TRI data are available. We measure whether a facility joined ISO 14001 by 2001 with the list of certified facilities published by the Center for Energy and Environmental Management (2000, 2001).

We also investigated alternative specifications for our dependent variable, including (1) a probit model where the two categories distinguish whether or not a facility was out of compliance for at least one month, (2) an ordered probit model where the three categories pertain to compliance for the entire period, in compliance for a part of the period, and out of compliance for the entire period, and (3) an event count model for the number of months out of compliance. For these approaches we used two-stage instrumental variables techniques (Khanna and Damon 1999; King and Lenox 2000; Welch, Mazur, and Bretschneider 2000); the results were substantively identical to treatment effects model presented here.

Below we first discuss firms' motivations for joining ISO 14001, corresponding to the first stage of our treatment effect model, and then discuss factors influencing facilities' regulatory compliance. The two sets of variables contain considerable overlap. For example, facilities may be more likely to join ISO 14001 if they receive frequent government inspections and frequent government inspections may improve facilities' compliance with environmental regulations. Since ISO 14001 was launched in late 1996, we control for such endogeneity problems by using information from 1995 and 1996 where possible and by using the treatment regression approach (Greene 1999).

The treatment effects model can be identified in two ways. First, as with instrumental variables models, we can include a variable that is correlated with the endogenous variable, excluded in the second-stage model, and is not correlated with the error term of the second stage. We choose to use the emissions variable as our instrumental variable on the assumption that a facility's emissions do not affect its compliance status except through emissions' influence on joining ISO 14001. On theoretical grounds, our rational is that for the most part clean air regulations do not directly specify the level of pollutants facilities are allowed to emit (Fiorino 1995). Rather, government

\footnotetext{
${ }^{9}$ Determining a facility to be out of compliance is a fairly serious matter, usually the end of a process that began with a "notice of violation" warning and continuing through several more regulatory steps (see Wood 1988). Government regulators determine compliance status, with facilities having some access to appeal.
} 
regulations instead govern the emission control technologies (e.g., "Best Available Control Technology") and reporting and tracking procedures facilities must adopt. Higher or lower emissions do not therefore directly translate into better or worse compliance levels. This identification strategy is valid if the instrumental variable (emissions) is uncorrelated with the errors of the second-stage equation, that is, if emissions does not effect current compliance other than via its influence on joining ISO $14001 .^{10}$ Second, the treatment model includes the predictor rho from the first-stage equation, in a manner similar to the Inverse Mills Ratio in a Heckman selection model. Since this variable is a nonlinear function of the variables in the selection equation, the second-stage model is identified even without instrumental variables via the normality assumption for the probit model (see Greene 1999). Our results do not hinge on whether or not we include emissions in the second-stage analysis.

\section{Section Equation for Joining ISO 14001}

Motivations for joining ISO 14001 may vary across different types of facilities and contexts. Here we describe the variables used in our first-stage analysis, most of which are included in the second stage, and their potential relationship with whether facilities join ISO 14001. We begin with a series of facility level measures, including facility "demographics" (size, pollution emissions) and policy variables reflecting the nature of regulator-facility interactions. We then discuss the policy context facing states and demographic makeup of the facilities neighborhood context.

Facilities facing more frequent inspections and enforcement actions may be more likely to join ISO 14001 to capture the benefits of ISO 14001's reputation with regulators. Facilities facing more rigorous inspection regimes are more likely to have regulators discover their violations. Inspections is the number of state and U.S. EPA inspections in 1995 and 1996. Enforcement actions is the number of enforcement actions including notices of violation levied by state and U.S. EPA officials against each facility in 199596. Penalty is the dollar amount of any monetary penalty assessed against the facility in 1995-96. Inspections, enforcement actions, and penalty are drawn from the EPA's IDEA database. Facility size is the number of employees, as reported in the Dunn and Bradstreet database. We also include two dummy variables measuring whether the facility is a branch facility (branch), single-site company (single), or company headquarters (scored zero). Finally,

${ }^{10}$ For an example, see Acemoglu, Johnson, and Robinson (2001). we include a series of dummy variables reflecting the facility's two-digit SIC code.

Facilities' compliance status may influence whether they join ISO 14001. For example, out of compliance facilities may be more likely to join the program, although given our data we are unable to identify whether this is because they value ISO 14001's reputation more or because of internal motives. To control for previous compliance, we include measures of each facility's regulatory enforcement and compliance history drawn from the EPA's AIRS/AFS system and included in its IDEA database. ${ }^{11}$ We measure facilities' previous regulatory compliance

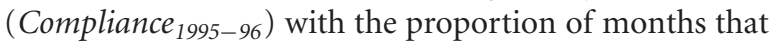
a facility is out of compliance over two year periods (1995-96 for our control variable, and 2000-2001 for our second-stage dependent variable). We also include the measure Compliance ${ }_{1995-96^{2}}$ since the effect of compliance on joining ISO 14001 may vary across levels of compliance. Emissions is the amount of air pollution emissions released by the facility in 1995 and 1996 as recorded in the TRI data, weighted by each pollutant's toxicity (King and Lenox 2000). Since additional units of pollution may also have varying marginal impact on whether firms join ISO 14001, we also include the measure emissions ${ }^{2}$ (emissions squared).

Facilities' environmental behavior may reflect their local context, for example because wealthier and more educated citizens might demand more environmental protection, or perhaps because more educated citizens are better equipped to identify and interpret the ISO 14001 brand name. We include several controls for the neighborhood context surrounding the facility. Residents' education measures the percentage of residents living within a threemile radius of a facility who have a high school education or greater, as reported in the U.S. EPA's IDEA database. From the same database, we also include control variables for the percentage of the area population who are minorities and the percentage of population making more than

\footnotetext{
${ }^{11}$ There are several possible explanations for the nonlinear specification of previous compliance. For example, always-in-compliance facilities may not join ISO 14001 perhaps because they already have positive reputation or a strong EMS, while always out of compliance companies may not desire to improve their environmental reputation or perhaps believe that joining ISO 14001 would cost more than the benefits it provides. The midrange companiesthose marginally out of compliance-may find ISO 14001 most attractive because they have the most to gain from ISO 14001's positive reputation. Arguably, always-in-compliance firms may want external verification of their regulatory performance and ISO 14001 may help in that. Always-out-of-compliance firms may see ISO 14001 as a tool to help them get in compliance, especially in jurisdictions where regulators have indicated that certification will lead to lesser penalties. In the results section, we investigate whether ISO 14001 reduces noncompliance more for facilities with.
} 
$\$ 75,000$ per year. The analysis includes the natural log of these three neighborhood context variables. ${ }^{12}$

The nature of government mandatory regulations may affect how facilities view ISO 14001. Green clubs operate in the shadow of public law and public regulatory institutions. Governments may make such green clubs cohere better with existing institutions through the mix of regulations, enforcement practices, and other programs they offer. Many states have developed their own voluntary programs, including some that have explicit EMS requirements. Some programs stipulate membership criteria, such as superior compliance histories. We measure whether states offer voluntary programs with two dummy variables, state EMS program, scored one if the facility is located in a state that sponsors its own EMS-based voluntary program, and state non-EMS program, scored one if the state sponsors a voluntary program that does not include an EMS component as reported in Crowe (2000). Our expectation is that the presence of voluntary programs, particularly EMS-based programs, encourages ISO 14001 adoption. $^{13}$

Regulatory stringency and regulatory flexibility are expected to significantly influence firms' perceptions of the attractiveness of voluntary programs (Gormley 1999; Scholz 1991; Scholz and Gray 1997; Winter and May 2001). Stringent regulations may lower the relative cost of joining ISO 14001 because facilities would have adopted rigorous management systems to comply with regulations anyway. Following Potoski (2001), we measure the stringency of state hazardous air pollutants regulations and ambient air standards with the dummy variables hazardous air regulations and ambient air regulations each scored one if the state's regulations are more stringent than the corresponding EPA minimum criteria. Our expectation is that facilities located in states with more stringent air pollution regulations are more likely to become ISO 14001 certified.

Part of the cost of joining ISO 14001 is the risk of receiving sanctions for violations uncovered during certification audits. About 25 states provide legal protections to firms that promptly disclose and correct violations un-

\footnotetext{
${ }^{12}$ In a few cases, these measures recorded zero residents making over $\$ 75,000$ (64 cases) or zero minority residents (26 cases), making natural logs problematic. One approach is to set the value for such cases at zero and add a dummy variable to account for any intercept shift (see Cameron and Trivedi 1998, 239-40). We experimented with this approach but were unable to get ML convergence; some standard errors were in question, although the reported coefficients were essentially identical to those presented here. In the analyses presented here we set the value at .05 for the zero cases for these measures.

${ }^{13}$ Note: these state programs are voluntary and do not cover all facilities in the state, only those that choose to join.
}

covered through audits (Housman 2001). Facilities may be more willing to join ISO 14001 (thereby committing themselves to external audits) if they are located in states that offer legal privilege and immunity to information uncovered during certification audits. We measure states' legal environment with the variable state audit protection, scored one if the state provides privilege or immunity protection for information uncovered in facilities' self-audits. State audit immunity and privilege protection laws and policies may not sufficiently assure firms that they will not be sanctioned for violations uncovered through selfaudits. Though the EPA supports voluntary audits and supports regulatory relief programs (1999), it opposes audit protection. Facilities in more litigious legal contexts may be less likely to adopt ISO 14001 out of fear that such self-incriminating evidence may be held against them. We measure state litigiousness using the ratio of environmental court cases to TRI facilities in each state. ${ }^{14}$

We also measure the extent to which regulators in each state severely punish violators (Gormley 1999; Scholz 1991; Winter and May 2001). Enforcement flexibility is the proportion of out of compliance facilities sanctioned through monetary penalties in the state where the facility is located. Enforcement flexibility may encourage ISO 14001 adoption because firms expect that self-reported violations will not always be severely punished. Finally, we control for states' political contexts with the number of members in the Sierra Club and the National Wildlife Federation per 1,000 residents in 1998. Facilities in states with stronger environmental groups may be more likely to join ISO 14001.

\section{Outcome Equation for Regulatory Performance}

A key test of green clubs such as ISO 14001 is whether they improve facilities' compliance with public law. Our dependent variable (Compliance $2000-01$ ) measures the proportion of months for which a facility was out of compliance in 2000 and 2001. The important independent variable is whether a facility has joined ISO 14001, ISO 14001, adjusted with the first-stage analysis. If ISO 14001 improves regulatory performance, facilities with higher predicted probabilities of joining ISO 14001 should spend less time out of compliance with environmental regulations. Since several state regulatory initiatives seek to improve regulatory facilities' performance, we include the measures: state audit protection, state EMS program, state

${ }^{14}$ Data are from Lexis Nexus State Case database searches with the key words "air pollution," "water pollution" and "hazardous waste" for the entire 1990s. 
TABLE 1 Descriptive Statistics

\begin{tabular}{|c|c|c|c|c|}
\hline Variable & Mean & Std. Dev & Min & Max \\
\hline \multicolumn{5}{|l|}{ Facility } \\
\hline Compliance $_{2000-01}$ & 0.114 & 0.299 & 0 & 1 \\
\hline Compliance $_{1995-96}$ & 2.25 & 6.21 & 0 & 24 \\
\hline Compliance $_{1995-96^{2}}$ & 43.57 & 137.59 & 0 & 576 \\
\hline Inspections & 2.10 & 2.34 & 0 & 42 \\
\hline Enforcement Actions & 0.430 & 1.86 & 0 & 50 \\
\hline Penalty & $6,369.04$ & $151,982.9$ & 0 & $9,000,000$ \\
\hline Emissions $_{1995-96}$ & $3.92 \mathrm{E}+08$ & $1.33 \mathrm{E}+09$ & 5 & $2.24 \mathrm{E}+10$ \\
\hline Emissions $_{1995-96^{2}}$ & $2.04 \mathrm{E}+18$ & $1.82 \mathrm{E}+19$ & 25 & $5.04 \mathrm{E}+20$ \\
\hline Number of Employees & 406.56 & 830.84 & 1 & 17500 \\
\hline Branch & 0.653 & 0.476 & 0 & 1 \\
\hline Single & 0.196 & 0.397 & 0 & 1 \\
\hline ISO 14001 & 0.040 & 0.196 & 0 & 1 \\
\hline \multicolumn{5}{|l|}{ Policy context } \\
\hline Litigiousness & 0.133 & 0.294 & 0.0115 & 2.64 \\
\hline Hazardous Air Regulations & 0.619 & 0.486 & 0 & 1 \\
\hline Ambient Air Regulations & 0.110 & 0.313 & 0 & 1 \\
\hline State audit protections & 0.522 & 0.500 & 0 & 1 \\
\hline State EMS programs & 0.213 & 0.410 & 0 & 1 \\
\hline State non-EMS program & 0.416 & 0.49 & 0 & 1 \\
\hline Regulatory Flexibility & 6.39 & 3.88 & 1.3333 & 24 \\
\hline Environmental Groups & 5.89 & 2.20 & 0.7778 & 14.16 \\
\hline \multicolumn{5}{|l|}{ Neighborhood context } \\
\hline Education & 81.26 & 6.73 & 58.1780 & 100 \\
\hline Income over $\$ 75,000$ & 4.36 & 22.27 & 0 & 100 \\
\hline Minorities & 21.87 & 4.08 & 0 & 100 \\
\hline
\end{tabular}

Sources indicated in text.

non-EMS program, enforcement flexibility, and hazardous air regulations and state ambient air regulations.

Many factors influence facilities' regulatory compliance, some of which we do not directly measure. However, we are able to control for many of these unobserved factors via facilities' previous compliance histories with our measure Compliance ${ }_{1995-96}$. Facilities' previous enforcement experiences may affect their current compliance status; we therefore include controls for enforcement actions, inspections, and penalty. Our analyses also include controls for facility size, facility type, manufacturing, and public and SIC code. Table 1 reports descriptive statistics of our data.

\section{Results Joining ISO 14001}

Table 2, column 1 reports results of our first-stage analysis examining the diffusion of ISO 14001 across facilities. The selection dependent variable is whether or not a facility joined ISO 14001 by December 2001 and the independent variables gauge current and past characteristics of the facility and regulatory climate. Interpreting the first-stage coefficients in Table 2 is complicated by probit's nonlinear functional form and by the fact that an occurrence of our dependent variable (an ISO 14001 certified facility) is quite rare. Following Long (1997), we calculate the discrete change in probability of our dependent variable occurring (a facility joins ISO 14001) given changes in our independent variables, holding all other variables at their mean. Note that these changes may seem quite small, but they should be interpreted relative to a "baseline" probability, which in our case is the rather small proportion of facilities joining ISO 14001 . Only about $4 \%$ of the facilities in our sample joined ISO 14001; holding all independent variables at their mean, the predicted probability of joining ISO 14001 is only .022. Overall, the first-stage model discriminates well among firms subscribing to ISO 14001: the chi-square statistic for the first stage only is 212.58 , significant at $\mathrm{p}<.001$. 
TABLE 2 Treatment Effects Analysis of Facilities Joining ISO 14001 and Their Regulatory Compliance

\begin{tabular}{|c|c|c|c|c|}
\hline & \multicolumn{2}{|c|}{ Joining ISO 14001} & \multicolumn{2}{|c|}{ Regulatory Compliance } \\
\hline & Coefficients & $\begin{array}{c}\text { Standard } \\
\text { Errors }\end{array}$ & Coefficients & $\begin{array}{c}\text { Standards } \\
\text { Errors }\end{array}$ \\
\hline \multicolumn{5}{|l|}{ Facility } \\
\hline Compliance $_{1995-96}$ & $1.61^{* *}$ & .686 & $.2831^{* *}$ & .026 \\
\hline Compliance $_{1995-96^{2}}$ & $-1.74^{* *}$ & .754 & & \\
\hline Inspections & $.030^{* *}$ & .0143 & $.009^{* *}$ & .003 \\
\hline Enforcement Actions & -.008 & .0162 & .006 & .004 \\
\hline Penalty & $-3.00 \mathrm{E}-08$ & $1.27 \mathrm{E}-07$ & $1.47 \mathrm{E}-08$ & $2.41 \mathrm{E}-08$ \\
\hline Emissions $_{1995-96}$ & $2.06 \mathrm{E}-10^{* *}$ & $6.86 \mathrm{E}-11$ & & \\
\hline Emissions $_{1995-96^{2}}$ & $-1.35 \mathrm{E}-20^{*}$ & $7.72 \mathrm{E}-21$ & & \\
\hline Number of Employees & $9.26 \mathrm{E}-05^{* *}$ & 0.000032 & $5.92 \mathrm{E}-06$ & $5.96 \mathrm{E}-06$ \\
\hline Branch & .112 & .111 & -.007 & .014 \\
\hline Single & -.039 & .144 & -.0255 & .016 \\
\hline ISO 14001 & & & $-.0768^{* *}$ & .034 \\
\hline SIC code dummies & Yes & & Yes & \\
\hline \multicolumn{5}{|l|}{ Policy context } \\
\hline Litigiousness & .081 & .128 & $.0757^{* *}$ & .022 \\
\hline Hazardous Air Regulations & $.281^{* *}$ & .111 & -.007 & .012 \\
\hline Ambient Air Regulations & .022 & .154 & $-.036^{* *}$ & .016 \\
\hline State audit protections & .020 & .099 & $.060^{* *}$ & .011 \\
\hline State EMS programs & -.069 & .124 & $-.060^{* *}$ & .014 \\
\hline State non-EMS program & .033 & .118 & -.009 & .014 \\
\hline Regulatory Flexibility & -.002 & .012 & $-.006^{* *}$ & .001 \\
\hline Environmental Groups & .027 & .022 & .0011 & .002 \\
\hline \multicolumn{5}{|l|}{ Neighborhood context } \\
\hline Education & $1.44^{* *}$ & .665 & -.094 & .076 \\
\hline Income over $\$ 75,000$ & .0081 & .031 & .002 & .004 \\
\hline Minorities & -.011 & .056 & .004 & .006 \\
\hline \multicolumn{5}{|l|}{ Constant } \\
\hline $\mathrm{N}$ & 3709 & & & \\
\hline Rho & 0.119 & & & \\
\hline Wald (independent eq.) & $10.71^{* *}$ & & & \\
\hline Wald (overall) & $705.84^{* *}$ & & & \\
\hline
\end{tabular}

${ }^{*} \mathrm{p}<.10,{ }^{* *} \mathrm{p}<.05$, two-tailed tests.

Facilities' compliance histories have an important impact on their ISO 14001 decisions. The relationship between the amount of time a facility was out of compliance in 1995 and 1996 and ISO 14001 registration follows an inverted U-shaped curve. The Compliance ${ }_{1995-96}$ Coefficient is statistically significant and positive while the Compliance ${ }_{1995-96^{2}}$ coefficient is statistically significant and negative. Facilities that are always in compliance or always out of compliance are the least likely to join ISO 14001. The predicted probability of joining ISO 14001 for facilities in compliance for the entire two-year period,
.01 is essentially the same as those who are not in compliance for the same time period (.01). For those who are out of compliance for about half the time, the predicted probability of joining ISO 14001 is about .018. The statistically significant coefficients for emissions and emissions $^{2}$ results suggest that low pollution facilities are least likely to join ISO 14001, while moderate and high polluting facilities are roughly equally more likely to join ISO 14001. Facilities that receive more regulatory inspections are significantly more likely to join ISO 14001. A two standard deviation increase in the number of inspections from 
one standard deviation below the mean to one above, increases the probability of becoming ISO 14001 certified from .019 to .026 .

Facilities in neighborhoods with more educated residents are more likely to join ISO 14001. A two standard deviation increase in the logged percentage of educated residents (from one standard deviation below the mean to one standard deviation above), increases the probability that a facility joins ISO 14001 from .016 to .030, holding the effects of other variables constant at their mean. This may be because ISO 14001's reputation is more valuable to facilities when local residents are better able to detect, interpret, and use the information, or perhaps because more educated residents have a higher demand for environmental performance.

Examining the measures of state-level policies, two features stand out. First, facilities in states with more stringent hazardous air pollution regulations are more likely to join ISO 14001. Joining ISO 14001 and adopting its stringent EMS requirements may help facilities meet higher regulatory standards. Second, our results indicate that most other government programs, laws, and regulations appear to have little influence on a facility's calculus about joining ISO 14001. None of the coefficients for enforcement actions, state audit protection, state EMS program, state non-EMS program, ambient air regulations, litigiousness, and regulatory flexibility achieved statistical significance in the analysis of why facilities join ISO 14001. Still, larger facilities, those with more employees, are significantly more likely to join ISO 14001.

Together, we can draw some tentative conclusions about why facilities join ISO $14001 .{ }^{15}$ First, government inspections spur facilities to join ISO 14001 as do more stringent hazardous air pollution regulations and more litigious regulatory climates. Other governmental policies appear to have little influence on facilities' ISO 14001 decisions, at least for state-level policies in U.S. air pollution regulation. With the EPA setting its own policies in areas such as audit privilege and immunity protection while also holding preemption authority over states that do not meet its minimum requirements for air pollution

\footnotetext{
${ }^{15}$ Ideally, our analysis would control for facilities' EMS prior to their joining ISO 14001 because facilities with high quality extant EMS would be more likely to join ISO 14001. Our analysis does somewhat control for the "prior EMS" effect through our controls for facilities' regulatory and environmental performance. Our model recognizes this issue and accordingly, we have already controlled for compliance 1995-1996 and emission 1995-1996, which serve in part as a proxy for "prior EMS." We do not claim that reputational benefits are the only reason facilities join ISO 14001 or adopt an EMS. Our claim is that because ISO 14001 has a nontrivial reputational benefit, a nontrivial amount of the reason facilities adopt ISO 14001 is due to the reputational benefit.
}

regulation, the variation in state policy contexts facing facilities may be too limited to influence their ISO 14001 certification decisions. Second, facilities with moderate compliance records are most likely to join ISO 14001 . Third, facilities in neighborhoods with more educated residents are more likely to join ISO 14001.

\section{ISO 14001 and Facilities' Regulatory Performance}

Table 2 column 3 reports the results of our analysis of the influence of ISO 14001 on regulatory compliance. Interpreting the second stage equations-facilities' compliance status-is more straightforward since the statistical method is akin to OLS. Second-stage coefficients can be interpreted as the change in the proportion of time spent out of compliance associated with a one unit increase in the independent variable. The results in Table 2 indicate that ISO 14001-certified firms spend less time out of compliance with clean air regulations than similarly situated noncertified facilities. The coefficient for ISO 14001 is .0768 and is statistically significant and negative. This implies that joining ISO 14001 reduced facilities' time spent out of compliance with clean air regulations controlling for other factors and the endogeneity between facilities decisions to join ISO 14001 and their regulatory compliance. ISO 14001 certified facilities spent about on average $11.4 \%$ of the time out of compliance while non-certified facilities spent about $12.5 \%$ of the time out of compliance. Importantly, this result persists while controlling for a variety of factors affecting firms' regulatory compliance, and perhaps most importantly, their previous regulatory compliance. Moreover, joining ISO 14001 was associated with better compliance records when we investigated other possible specifications-OLS, probit, ordered probit, event count models - again while controlling for other factors. Finally, the rho coefficient (.121) and the Wald test for independent equations (12.38) are statistically significant, indicating that our treatment adjustments are justified.

An important question regarding voluntary program is whether to restrict membership to strongly performing facilities, such as those with perfect compliance records, or to open it more broadly to include those with the most room for improvement. Government sponsored programs tend to restrict membership eligibility to stronger performers while nongovernmental voluntary programs, such as ISO 14001 have broader eligibility. To investigate this issue, we reanalyzed our data restricting our sample to only those facilities with perfect compliance records; the coefficient for ISO 14001 was only .065, less the ISO 
14001 coefficient for the full sample including less than perfect compliers. This implies that ISO 14001 produces a greater reduction in noncompliance for facilities that in the past have not been in compliance with government regulations.

The finding that joining ISO 14001 appears to improve facilities' regulatory compliance has important implications. The credibility of green clubs is not strong among environmental activists (Steinzor 1998) and the academic literature on their performance is uneven (compare, for example, King and Lenox 2001 with Khanna and Damon 1999). Our analysis should support the credibility of ISO 14001 by showing that joining ISO 14001 does improve regulatory compliance beyond what likely would have occurred had the facilities not joined.

The Table 2 results for regulatory compliance also suggest that several state-level policies are associated with varying levels facilities' compliance performance, although we must be careful about interpreting these coefficients. Regulatory flexibility is associated with improved compliance; facilities in states where regulators are less likely to fine for noncompliance are more likely to be in compliance with clean air regulations. Likewise, facilities in states with government sponsored voluntary programs have better compliance records than facilities in states without these programs. These results are consistent with previous research that suggests that cooperation between regulators and facilities can improve regulatory compliance (Scholz 1991). Finally, facilities in states with more stringent ambient air quality regulations have stronger compliance records, and facilities in states with more litigious legal contexts and environmental audit privilege and immunity laws have worse compliance records. We should note that our data do not indicate whether these state policies, practices, and regulations are a cause or consequence of facilities' compliance performance. For example, states may adopt flexible regulatory enforcement in order to improve compliance or states may be more flexible because facilities in their state already have solid compliance records. Facilities' compliance histories influence their future compliance status. Facilities that were out of compliance in 1995 and 1996 were significantly more likely to be out of compliance in 2000 and 2001. Likewise, facilities that received more inspections and enforcement actions in 1995 and 1996 were significantly more likely to be out of compliance in 2000 and 2001.

\section{Conclusion}

Why firms join voluntary programs and whether these programs improve firms' compliance with governmen- tal law are debated issues in environmental policy. We conceptualize voluntary codes as club goods that provide nonrival but potentially excludable benefits to firms, while producing a more general public good of cleaner environment and better compliance with the law. Viewing voluntary programs as club goods helped us to identify relevant analytic features, specifically reputational (club) benefits and exclusion mechanisms, that may help explain why different voluntary regulations work better in some contexts than others. Drawing on interviews with facility managers and government regulators along with reviews of the literature, we first show that joining ISO 14001 both carries a reputational benefit and imposes costs on a member looking to join. Results from our empirical analysis imply that joining ISO 14001 reduces facilities' time spent out compliance by about $7 \%$, or about 25 days out of a year. We also found that some government policies such as the frequency with which facilities receive inspections and the stringency of regulations compel facilities to join ISO 14001. However, other government policies appear to have little influence on whether or not facilities join ISO 14001.

Our study of ISO 14001 suggests some tentative conclusions about designing effective voluntary programs. Effective clubs must overcome two collective action problems successfully to provide a broader public benefit. First, they must induce sufficient members to take on the costs of joining the club. They can do so by providing members a nonrival but potentially excludable reputational benefit. Second, to produce public benefits, effective clubs must ensure members continue to adhere to club standards, which in the case of ISO 14001 leads to better compliance with governmental regulations. We conjecture that ISO 14001's EMS-based approach mitigates noncompliance rooted in ignorance by focusing on the root causes of noncompliance (Brehm and Hamilton 1996; Winter and May 2001). A repeated theme in our interviews with regulators and managers is that ISO 14001's external audit helped safeguard against willful shirking. This mitigates free-riding issues, leads to better adherence to club standards, and therefore to better compliance with governmental regulations. Preventing shirking through external audits may spur a virtuous cycle of trust begetting more trust, as members are more likely to contribute to the maintaining the club's reputation because they believe other members will do so as well (Scholz and Lubell 1998). At a broad level, voluntary programs may serve as institutionalized, and therefore more credible, mechanisms for building trust between firms and regulators (Potoski and Prakash 2004b).

There are important grounds for tempering our conclusions about how ISO 14001 fits with extant regulatory 
structures. First, while our empirical evidence implies that ISO 14001 is effective at improving members' regulatory compliance, our analysis is observational and quasiexperimental, and consequently risks the imperfections of all such studies. For example, since we lack data on what other voluntary programs facilities have joined, it is possibility that some of the credit we attribute to ISO 14001 should accrue to these other programs. We have sought to address these weaknesses with statistical controls and a grounded theoretical approach. Second, we do not claim that voluntary regulation can replace mandatory regulations nor do we claim that ISO 14001 would still be effective if mandatory regulations were weaker. Effective voluntary regulations may require certain conditions to be effective, such as economies with well developed corporate and product brand identities or stringent environmental regulations (authors forthcoming). More fundamentally, an effective voluntary regulation may compliment command and control. In command and control, cooperation between firms and government regulators may be more effective than conflict, but only if both sides cooperate (Scholz 1991). Joining an effective voluntary program may institutionalize firms' commitment to cooperating with government regulators.

Our inquiry in this article suggests several venues for future research. An obvious extension is to look beyond regulatory compliance and examine whether joining ISO 14001 improves facilities' environmental performance, that is, reduces their pollution emissions. Also, there are strong theoretical reasons to suspect that the efficacy of voluntary programs may vary across policy and regulatory contexts. Future research should focus on comparing ISO 14001 to other voluntary programs, both governmental and nongovernmental, across countries and perhaps across states using more nuanced measures and data. And finally, the mixed findings reported in the literature on the efficacy of different types of voluntary programs suggest the need for continuing research that explicitly compares across programs to better understand how varying program features contribute to their success.

\section{References}

Acemoglu, Daron, Simon Johnson, and James A. Robinson. 2001. "The Colonial Origins of Comparative Development: An Empirical Investigation." American Economic Review 91(5):1329-49.

Ayres, Ian, and John Braithwaite. 1992. Responsive Regulation. Oxford: Oxford University Press.

Brehm, John, and James T. Hamilton. 1996. "Noncompliance in Environmental Reporting: Are Violators Ignorant, or Evasive, of the Law?" American Journal of Political Science 40(2):444-77.
Buchanan, James M. 1965. "An Economic Theory of Clubs." Economica 32(February):1-14.

Carpenter, Daniel P. 1996. "Adaptive Signal Processing, Hierarchy, and Budgetary Control in Federal Regulation." American Political Science Review 90(2):283-302

Carpenter, Daniel P. 2001. The Forging of Bureaucratic Autonomy: Networks, Reputations and Policy Innovation in Executive Agencies, 1862-1928. Princeton: Princeton University Press.

Cameron, A. Colin, and K. Pravin Trivedi. 1998. Regression Analysis of Count Data. New York: Cambridge University Press.

Center For Energy And Environmental Management. 2000. ISO 14001 Registrations-North America. Update. Extra Edition, September 2000.

Center for Energy and Environmental Management. 2001. ISO 14001 Registrations-North America. Update. Extra Edition, September 2001.

Cornes, Richard, and Todd Sandler. 1996. The Theory of Externalities, Public Goods, and Club Goods. Cambridge, MA: Cambridge University Press.

Crowe, Michael. 2000. "Beyond Experiments." The Environmental Forum 17(3):20-29.

Dasgupta, Susmita, Hemamala Hettige, and David Wheeler. 2000. "What Improves Environmental Compliance? Evidence from Mexican Industry." Journal of Environmental Economics and Management 39(1):39-66.

Environmental Protection Agency (EPA). 1999. Action Plan for Promoting the Use of Environmental Management Systems. December 20, 1999.

Fiorino, Daniel J. 1995. Making Environmental Policy. Berkeley: University of California Press.

Fiorino, Daniel. J. 1999. "Rethinking Environmental Regulation.” Harvard Environmental Law Review 23(2):441-69.

General Accounting Office (GAO). 1983. Waste Water Dischargers Are Not Complying with EPA Pollution Control Limits, RECED 84-53: Washington, D.C.

Gerber, Brian, and Paul Teske. 2000. "Regulatory Policy-Making in the American States: A Review of Theories and Evidence." Political Research Quarterly 53(4):849-86.

Gormley, William T., Jr. 1999. "Regulatory Enforcement Styles.” Political Research Quarterly 51(2):363-83.

Greene, William H. 1999. Econometric Analysis. $4^{\text {th }}$ ed. New York: Prentice-Hall.

Greenstone, Michael, and Kenneth Chay. 2004. "Does Air Quality Matter? Evidence from the Housing Market." Mimeograph. University of California, Berkeley.

Gunningham, Neil A., Robert A. Kagan, and Dorothy Thornton. 2003. Shades of Green: Business, Regulation, and Environment. Stanford: Stanford University Press.

Hale, Rhea, 1998. The National Expansion of Star Track. Boston: Environmental Protection Agency, Region I.

Haufler, Virginia. 2001. A Public Role for the Private Sector. Washington: Carnegie Endowment for International Peace.

Hoffman, A.J. 1997. From Heresy to Dogma. San Francisco: New Lexington Press.

Housman, V.A. 2001. State Audit Privilege and Immunity Laws, email, November 16, 2001. On file.

ISO. 2003. The ISO Survey of ISO 9000 and ISO 14000 certificates Twelfth Cycle, http:/www.iso.ch/iso/en/iso9000-14000/ iso14000/iso14000index.html, Accessed February 9, 2003. 
ISO. 2002. Environmental Management: The ISO 14000 Family of International Standards, http://www.iso.ch/iso/en/prodsservices/otherpubs/iso14000/index.html, 06/02/2003.

Jaffe, Adam, Steven Peterson, Paul Portney, and Robert Stavins. 1995. "Environmental Regulation and the Competitiveness of U.S. Manufacturing." Journal of Economic Literature 33(1):132-63.

King, Andrew, and Michael Lenox. 2000. "Industry SelfRegulation without Sanctions: The Chemical industry's Responsible Care Program." Academy of Management Journal 43(August):698-716.

Khanna, Madhu, and Lisa Damon. 1999. “EPA's Voluntary33/50 program: Impact on Toxic Releases and Economic Performance of Firms." Journal of Environmental Economics and Management 37(1):1-25.

Kolk, Ans. 2000. The Economics of Environmental Management. New York: Prentice Hall/Financial Times.

Kollman, Kelly, and Aseem Prakash. 2001. "Green by Choice? Cross-National Variations in Firms' Responses to EMS-based Environmental Regimes.” World Politics 53(April):389-430.

Long, J. Scott. 1997. Regression Models for Categorical and Limited Dependent Variables. Thousand Oaks: Sage Publications.

Lubell, Mark, Mark Schneider, John Scholz, and Mihriye Mete. 2002. "Watershed Partnerships and the Emergence of Collective Action Institutions." American Journal of Political Science 46(1):148-63.

Pfaff, Alexander S.P., and Chris William Sanchirico. 2000. "Environmental Self-Auditing: Setting the Proper Incentives for Discovery and Correction of Environmental Harm." Journal of Law Economics and Organization 16(1):189-208.

Potoski, Matthew. 2001. "Clean Air Federalism: Do States Race to the Bottom?" Public Administration Review 61(3):33542.

Potoski, Matthew, and Aseem Prakash. 2004a. "Regulatory Convergence in Nongovernmental Regimes: Cross-National Adoption of ISO 14001 Certification." Journal of Politics 66(3):885-905.

Potoski, Matthew, and Aseem Prakash. 2004b. “The Regulation Dilemma: Conflict and Cooperation in Environmental Governance." Public Administration Review 64(2):137-48.
Prakash, A. 2000a. "Responsible Care: An Assessment.” Business \& Society 39(2):183-209.

Prakash, A. 2000b. Greening the Firm. New York: Cambridge University Press.

Ringquist, Evan. 1993. Environmental Protection at the State Level: Politics and Progress in Controlling Pollution. Armonk: M.E. Sharpe.

Schneider, Mark, John Scholz, Mark Lubell, Denisa Mindruta, and Matthew Edwardsen. 2003. "Building Consensual Institutions: Networks and the National Estuary Program.” American Journal of Political Science 47(1):143-58.

Scholz, John. T. 1991. "Cooperative Regulatory Enforcement and the Politics of Administrative Effectiveness." American Political Science Review 85(1):115-36.

Scholz, John T., and Mark Lubell. 1998. "Adaptive Political Attitudes: Duty, Trust and Fear as Monitors of Tax Policy." American Journal of Political Science 42(July):398-417.

Scholz, John T., and Wayne B. Gray. 1997. "Can Government Facilitate Cooperation? An Informational Model of OSHA Enforcement." American Journal of Political Science 41(July):693-717.

Steinzor, Rena. I. 1998. "Reinventing Environmental Regulation: The Dangerous Journey from Command to SelfControl." Harvard Environmental Law Review 22(1):103.

Walley, Noah, and Bradley Whitehead. 1994. "It's Not Easy Being Green." Harvard Business Review 72(3):46-51.

Welch, Eric, Alllan Mazur, and Suart Bretschneider. 2000. "Voluntary Behavior by Electric Utilities.” Journal of Policy Anal$y$ sis and Management 19(Summer):407-25.

Williamson, Oliver. 1985. Economic Institutions of Capitalism. New York: Free Press.

Winter, Soren, and Peter May. 2001. "Motivation for Compliance with Environmental Regulations." Journal of Policy Analysis and Management 20(4):675-98

Wood, B. Dan. 1988. "Bureaucrats, Principals, and Responsiveness in Clean Air Enforcements." American Political Science Review 82(2):215-34.

Wood, B. Dan, and Richard W. Waterman. 1993. "The Dynamics of Political-Bureaucratic Adaptation." American Journal of Political Science 37(2):497-528. 